\title{
Effect of personality on compound reasoning
}

\section{Efecto de la personalidad en el razonamiento compuesto}

\author{
Maria del Carmen Crivello ${ }^{\mathrm{a}, \mathrm{b}, *}$, Eugenia Razumiejczyk ${ }^{\mathrm{a}, \mathrm{b}}$, Guillermo Macbeth ${ }^{\mathrm{a}, \mathrm{b}}$ \\ aUniversidad Católica Argentina, Argentina \\ ${ }^{b}$ National Scientific and Technical Research Council, Argentina
}

\begin{abstract}
Objective: this study aims to describe the relationship between personality and propositional reasoning regarding compound negations by using, in particular, De Morgan's laws. Method: to evaluate personality traits, we used the Adjective Checklist for Personality Assessment, an instrument based on the Big Five theory and developed for the Argentine context. To assess reasoning, we used a task implemented in previous studies, according to which subjects had to find the logical equivalent of a compound negation. Four response options were offered: one was correct and the other three were linked to specific biases. Both the research study and the paradigm were developed on the basis of the Mental Models Theory of Negation. The study had a correlational design and included 150 university students. Results: we found that factors such as neuroticism, extraversion, and agreeableness were linked to specific response patterns. Difficulty and context were considered mediators of the process. Discussion: the evidence was compatible with the Mental Models Theory but inconsistent with theories based on formal rules.
\end{abstract}

Keywords: mental models; compound negation; reasoning biases; personality factors.

\section{Para citar este artículo:}

Crivello, M. C., Razumiejczyk, E., \& Macbeth, G. (2020). Effect of personality on compound reasoning. Liberabit, 26(1), e313. https://doi.org/10.24265/liberabit.2020.v26n1.04

\section{Resumen}

Objetivo: el propósito de este estudio es describir la relación entre personalidad y razonamiento proposicional sobre negaciones compuestas, de forma particular aplicado a las leyes De Morgan. Método: para evaluar los rasgos de personalidad se utilizó el Listado de Adjetivos para Evaluar Personalidad, un instrumento basado en la Teoría de los Cinco Factores desarrollado para el medio Argentino. En el caso del razonamiento, se aplicó una tarea utilizada en estudios previos, en la cual el sujeto debía encontrar el equivalente lógico de una negación compuesta. Se ofrecieron cuatro opciones de respuesta, una correcta y tres ligadas a sesgos específicos. Tanto la investigación como el paradigma, fueron diseñados desde la Teoría de Modelos Mentales propuesta para la negación. El estudio fue de tipo correlacional, y participaron del mismo 150 estudiantes universitarios. Resultados: se encontró que los factores de Neuroticismo, Extraversión y Amabilidad estaban ligados a patrones de respuestas específicos. La dificultad y el contexto fueron considerados mediadores del proceso. Discusión: la evidencia resultó compatible con la Teoría de Modelos Mentales pero inconsistente respecto de las teorías basadas en reglas formales.

Palabras clave: modelos mentales; negación compuesta; sesgos de razonamiento; factores de personalidad.

Este es un artículo Open Access bajo la licencia Creative Commons Atribución-NoComercial-CompartirIgual 4.0

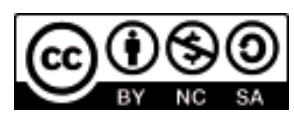




\section{Introduction}

One of the features most evoked when theorizing about humans is the ability to think. Although this quality was recognized by prominent philosophers (Aristotle, 1984), there are intense debates when it comes to explaining how it works. When people start to analyze this field, they have to deal with a reality both ubiquitous and controversial: an overwhelming amount of empirical evidence questions the very rationality of human thought, which would no longer seem to be the product of a logical and organized process but the result of a varying number of interacting elements (Airenti, 2019).

A paradigmatic example of this issue can be found when studying the processing of negation. This phenomenon, easily explained by mathematical logic (Macbeth, Crivello, Fioramonti, Razumiejczyk, 2017a), nevertheless presents some difficulties when processed by the human mind. Some approaches tried to account for this complexity and proposed the intervention of pragmatic (Horn, 1989; Horn \& Ward, 2005; Orenes, Moxey, Scheepers, \& Santamaría, 2016), contextual (Sperber \& Wilson, 1986; Wilson \& Sperber, 1994) and conversational (Bott \& Noveck, 2004; Grice, 1989) factors. Despite these efforts, it was not however until the proposal of Khemlani, Orenes, and Johnson-Laird $(2012,2014)$ that a complete Theory of Negation was presented. To develop this theory, the authors extended the findings formulated in the Mental Models Theory - MMT (Johnson-Laird, 1983, 2006, 2010a, 2010b; Johnson Laird \& Byrne, 1991; Johnson-Laird, Goodwin, \& Khemlani, 2018; Johnson-Laird \& Ragni, 2019). The latter was born in opposition to traditional theories like the Psychology of Proof - PSICOP (Rips, 1994, 2011) or the Mental Logic Theory (Braine \& O’Brien, 1998), which consider reasoning to be a set of innate logical rules (Elqayam \& Over, 2016).

While logicist theories emphasize the formal and syntactic aspects of thought, the MMT focuses on the semantic and contextual components (Khemlani,
2018; Macbeth, Razumiejczyk, Crivello, Fioramonti, \& Pereyra-Girardi, 2013). The general hypothesis is that people reason by developing mental models of the world (Khemlani, Byrne, \& Johnson-Laird, 2018; Johnson-Laird \& Ragni, 2019). These models are defined as iconic representations of the world (Johnson-Laird, 2006). Their elaboration depends on the interaction between people's knowledge and the information received from outside (Johnson-Laird, 2010b, Johnson-Laird, Khemlani, \& Goodwin, 2015; Khemlani \& Johnson-Laird, 2017). In this way, when individuals understand the world, what they do is to mentally represent a different set of possibilities, compatible with the information obtained (JohnsonLaird, 1983). Another fundamental characteristic of the MMT is that the difficulty to process information is regulated by the number of mental models necessary for its representation. Thus, the greater the number of models required, the greater the difficulty (Johnson-Laird, 1983). Additionally, it postulates that people naturally tend to avoid overloading their working memory (Johnson-Laird, 1983, 2006, 2010a; Khemlani, 2018). Based on these assumptions, the MMT predicts some behaviors that take place when people reason. For example, when reasoning about compound propositions, that is, a proposition made up of two atomic sentences joined by a connector (and, or, if... then... among others), the MMT predicts differential behaviors according to the connector involved (Johnson-Laird, 2010b; Khemlani et al., 2014). We will take up these questions later.

Along with reasoning, another phenomenon that received great attention within the field of psychology is that of personality. Saying that personality has an influence on the way we think is not a surprising statement, but to postulate that it is possible to predict concrete ways of reasoning depending on personality is so indeed. In this sense, in a study aimed to assess the effect of personality on human reasoning, defenders of the MMT proposed the general hypothesis that individual personality styles could have inferential consequences in reasoning (Fumero, Santamaría, Johnson-Laird, 2010). According to these 
authors, since reasoning is a semantically driven process based on the generation of possibilities, the fact that considering one or another possibility may be influenced by personality characteristics is entirely plausible (Fumero et al, 2010). In this study, partial evidence confirmed the stated hypothesis. Although other research studies have been carried out along the same lines (Castro Solano \& Casullo, 2001; Restrepo, 2015) and other related ones, like the study of individual differences linked to thinking dispositions and cognitive styles (Stanovich, 2012; Sternberg, Grigorenko, \& Zhang, 2008), there has been no studies on the effect of personality on reasoning, particularly with compound negation. In this way, the relationship between both aspects, reasoning with compound negation and personality, acquires a central importance here.

\section{The Theory of Negation}

Negation is a fundamental element of natural language (Horn, 1989). It appears in all human languages, although it does not have the same grammar structure in all of them (Khemlani et al., 2012). Its importance is evidenced by the attention received from various disciplines, especially in the study of propositional reasoning (Macbeth et al., 2013; Macbeth, Razumiejczyk, Crivello, Fioramonti, \& Pereyra-Girardi, 2015; Orenes et al., 2016).

According to Khemlani et al. (2012), while the goal of a Linguistic Theory of Negation is to explain its syntactic, semantic and pragmatic elements, the purpose of a Psychological Theory is to explain how such grammar, meaning, and knowledge are understood by people and how people represent them mentally. And here lies the central goal of the proposal: to decipher the meaning, representation, and use granted by people to negation (Khemlani et al., 2012, 2014; Macbeth et al., 2013, 2017a). Out of all these elements, meaning is the one which acquires fundamental value, due to its effect on negation (Khemlani et al., 2012, 2014). Thus, given any proposition, the MMT postulates that individuals use the meaning to represent it mentally. This meaning is a product of their knowledge of the world, and of the contextual factors that intervene in the moment (Johnson-Laird, 1983, 2006; Johnson-Laird et al., 2015, 2018). The representation is produced using mental models (Johnson-Laird, 1983; 2006; JohnsonLaird et al., 2015, 2018), the scale of which will be linked to the scope of the subject's interpretation of the proposition (Khemlani et al., 2012).

In this way, the Theory of Negation works with the assumptions of the MMT and defines it as a function that takes the set of mental models as a single argument, and produces the complement for that set as a result (Khemlani et al., 2012, 2014; Macbeth et al., 2013; 2014b, 2017a). In this sense, the meaning of negation coincides with that proposed by logic (Khemlani et al., 2012). For both, the relationship between an affirmation and its negation is of mutual contradiction, and the possibilities between both are complete and exhaustive (Khemlani et al., 2012, 2014). Since inferences are based on mental models, the MMT also considers that people will only succeed in their reasoning if they start from properly represented premises (Khemlani et al., 2012). In this way, the number of mental models takes on a crucial role. According to the model, as the number of possibilities that subjects must represent increases, so does the overload in their working memory (Khemlani, 2018; Khemlani et al., 2012, 2014, 2017, 2018). Consequently, the task becomes more difficult, while both time to resolution and tendency to error increase (Khemlani, 2018; Khemlani et al., 2012, 2014, 2017, 2018).

Starting from these assumptions, five main predictions derive from the Theory of Negation (Khemlani et al., 2012); however, we will only focus on three of them in this research. One of these predictions (prediction 1 of the Theory of Negation) is related to the scope of the subject's interpretation of a proposition. According to the theory, given the negation of a compound proposition, that is, a proposition made up of two atomic sentences joined 
by a connector (and, or, if... then...), the individual tends to represent the negation by considering only one of the atomic propositions, and not the proposition composed in its entirety (Khemlani et al., 2012; Macbeth et al., 2013). This form of representation is called small scope and corresponds to a processing bias that people use whenever they have the opportunity (Khemlani et al., 2012). This interpretation also implies the representation of a smaller number of mental models (hence the name of the bias), and consequently a lower overload in working memory (Khemlani et al., 2012; Macbeth et al., 2013).

A second prediction (prediction 3 of the Theory of Negation) establishes that the interpretation of a compound proposition is also modulated by the meaning, knowledge, and reference people assign to the connectives involved. This is fundamentally determined by the use people give them in everyday language (Khemlani et al., 2012). According to this prediction, this modulation can interfere, or even block, the correct interpretation of a proposition, especially in the case of individuals who do not have training in logic (Khemlani et al., 2012).

Finally, a third prediction (prediction 5 of the Theory of Negation) establishes that propositions that require the representation of a single mental model are easier to interpret than those that require more mental models. The interesting thing about this prediction is that it also postulates that difficulty is reversed in the case of a negation (Khemlani et al., 2012). This characteristic arises as an effect of the complementarity condition described above. Thus, the complement of a single mental model requires the representation of several mental models, while the complement of a set of mental models requires only one or two (Khemlani et al., 2012).

This last prediction is clearly expressed in De Morgan's laws. As these laws formally establish, the negation of a conjunction is equivalent to an inclusive disjunction (Law 1), while the negation of an inclusive disjunction is equivalent to a conjunction (Law 2) (De
Morgan, 1847; Suppes \& Hill, 1992). Since the representation of a conjunction requires a single mental model, and the representation of an inclusive disjunction involves three mental models, the theory predicts greater difficulty in processing Law 1 than Law 2 (Macbeth et al., 2014b; 2017a).

In this way, the purpose of this study is to analyze the propositional reasoning of both laws in relation to the natural language of people. In particular, it aims to test the aforementioned predictions. It should be borne in mind, however, that such predictions will only make sense in a theory that considers the representation of mental models as a general mechanism of reasoning. This hardly happens in the case of theories based on logicist assumptions (Khemlani et al., 2012).

\section{Personality}

The theories of personality have changed greatly and have accompanied the development of psychology since its inception. As from the 1970s, a proposal seems to gain momentum with each passing day: the Theory of Personality founded on the Five Factor Model - FFM (McCrae \& Costa, 1987; 1999; 2004; Costa, McCrae, \& Löckenhoff, 2019; McCrae \& Mõttus, 2019). This model proposes a pentafactorial structure of personality, according to which variations in behavior and overt acts are explained around five big personality traits: the Big Five (Sánchez \& Ledesma, 2007). These factors are called neuroticism, extraversion, openness, agreeableness, and conscientiousness (McCrae \& Costa, 2004; McCrae \& Mõttus, 2019).

An important aspect of the proposal is that these dimensions are not the result of the free inventiveness of researchers but of numerous empirical studies (McCrae \& Mõttus, 2019; Sánchez \& Ledesma, 2007). Concurrently, several studies support the existence of these five factors, in which genetic predisposition plays a fundamental role (Costa \& McCrae, 1999; Laajaj et al., 2019; van der Linden, 
2019). Such structure has been proved independent of language, religion, and culture (Allik \& McCrae, 2002; Laajaj et al., 2019; McCrae \& Terraciano, 2005; van der Linden, 2019). According to these authors, the fact that these regularities are manifested in diverse cultures and contexts suggests the presence of basic characteristics in humans. This conception, however, does not seek to deny the role of the environment. On the contrary, it provides the final conditions for people’s development (Sánchez \& Ledesma, 2007).

The FFM offers a general description of the factors and attributes second-order factors called facets to each of them (Sánchez \& Ledesma, 2007). Using these descriptors as a reference, it is possible to outline the distinctive characteristics of people according to their preponderant factor. Thus, an individual who scores high in agreeableness can probably be described as generous, considerate, supportive, altruistic, and conciliatory (Ledesma, Sánchez, \& Díaz-Lázaro, 2011). The agreeableness factor can be understood as altruistic because it is concerned with the benefit of others in situations that might result in total loss of benefits for everyone. A person whose central feature is neuroticism will probably be anxious, unsteady, undecided, might worry a lot, and be prone to rumination (Introzzi, Andrés, Canet-Juric, Stelzer, \& Richard’s, 2016; Pereira et al., 2012). An individual characterized by extraversion is surely sociable, talkative, spontaneous, full of energy, and excitement seeking; on the other hand, if openness predominates, the person will be imaginative, adventurous, creative, original, and non-conservative (Ledesma et al., 2011). Finally, a subject with the conscientiousness trait is probably persistent, organized, cautious, tidy, and productive (Ledesma et al., 2011).

Another distinctive aspect of the FFM is the emphasis placed on evaluation (Sánchez \& Ledesma, 2007). Several instruments have been developed around the Big Five theory. In general, these are selfadministered instruments composed of adjectives or short phrases from which one seeks to infer basic personality trends. One of the most successful instruments is the NEO-FFI (McCrae \& Costa, 2004). This questionnaire has proven to be very useful, reliable, and valid in many contexts (McCrae \& Costa, 2004; McCrae \& Mõttus, 2019). Another instrument of interest here is the Adjective Checklist for Personality Assessment (AEP), developed by Ledesma and collaborators for the Argentine population (Ledesma et al., 2011; Sánchez \& Ledesma, 2013). The AEP replicated, at the local level, the findings of the FFM worldwide, proving to be of great regional value (Ledesma et al., 2011; Sánchez \& Ledesma, 2013).

If we understand the concept of trait as a relatively stable predisposition to react to the environment (Allport, 1974), it is not strange to think that traits can influence the way we reason. Along this line, Fumero et al. (2010) argue that if reasoning is a semantically driven process according to which we imagine possible worlds, then the ability to consider one or another possibility can be linked to characteristics of our personality. Under these assumptions, the authors postulate that those individuals who score high in a certain personality trait perform better in tasks in which the contents are linked to that trait. For example, extrovert individuals would reason better in social situations, while those who tend to be neurotic perform better in anxiogenic situations (Fumero et al., 2010). The general idea is that our personality has inferential consequences. This hypothesis has been partially confirmed by empirical evidence (Fumero et al., 2010). Sternberg et al. (2008), for example, were interested in studying the relationship between personality and school performance from the perspective of cognitive styles. On the other hand, Castro-Solano and Casullo (2001) have warned that intellectual factors alone are poor predictors of academic performance, while pointing out that certain personality dimensions enable to distinguish between profiles of high and low school performance. More recently, other studies (Brandt, Lechner, Tetzner, \& Rammstedt, 2019; Stajkovic, 
Bandura, Locke, Lee, \& Sergent, 2018) have also been interested in the influence of personality traits and cognitive ability on academic performance. Finally, Macbeth, Razumiejczyk and Campitelli (2011) and Macbeth, Razumiejczyk, \& and Crivello (2014a) have presented evidence in favor of introspection as an intervening variable in logical reasoning.

The aim of this study was to describe the relationship between personality and reasoning. Our working hypothesis stated that neuroticism, extraversion, and agreeableness generate specific response patterns in compound reasoning tasks concerned with negation. Literature on reasoning in general and the MMT in particular confer great importance to difficulty and context as intervening factors in the reasoning process (Khemlani \& Johnson-Laird, 2016; Macbeth et al., 2013; Markovits, Brisson, \& Chantal, 2016; Valiña, Martin, \& Seoane, 2014). In this study, although none of these phenomena are particularly considered in the statistical analysis, we nevertheless assume their existence as mediating factors of the process.

This paper continues as follows. First, we introduce our experimental paradigm to evaluate reasoning. Then, we present five experimental hypotheses derived from the working hypothesis included in the Method section. Afterwards, we continue with replication details related to participants, design, materials, and procedure. The statistical results are discussed in the context of previous evidence. Finally, the General Discussion section covers the scope and limitations of the contribution of this study in the context of the current state of the art.

\section{Paradigm}

When evaluating reasoning, two variables are of particular interest: response time and response type. In this study, we have focused on response type. Thus, we chose an experimental paradigm that was specifically designed to evaluate propositional reasoning regarding compound negations. It is a selection test used in previous studies (Macbeth et al., 2015; 2017a), in which subjects are asked to select a response option that they consider appropriate. Given that the paradigm was also based on the MMT, it presupposes a close relationship between each specific response and specific mental models leading to such selection.

The task begins with a statement that describes an everyday situation. The statement is formulated in colloquial language but made in such a way that it contains one of De Morgan's laws in its internal structure. In other words, the statement that represents Law 1 contains an internal structure of no type ( $p \& q$ ) (see Figure 1), while the statement of Law 2 is of no type ( $p$ or $q$ ) (see Figure 2), where the letters $p$ and $q$ symbolize atomic propositions. The instruction involves choosing from a set of options the one that best represents the situation described. In terms of reasoning, subjects have to find the logical equivalent of the proposition. Two statements are considered to be logically equivalent when they express the same idea (Macbeth et al., 2017a).

The answer options are four: one corresponding to the normative response, and three corresponding to additional erroneous statements. The normative response is the one that captures the logical equivalent for each of De Morgan's laws (De Morgan, 1847) in its internal structure. In the case of Law 1, the correct answer is of no $p$ or no $q$, nor any type (see Figure 1 , option a), while in the case of Law 2 it is of no $p$ $\&$ no $q$ type (see Figure 2, option d). As regards the number of mental models required in each case, it is clear that the task related to Law 1 is more difficult than the one related to Law 2, since the resolution of the first one requires the representation of three mental models, while for the second, only one is necessary (Macbeth et al., 2014b; 2017a).

Regarding the other options, although they are erroneous, they do not lack theoretical relevance. On the contrary, each has different logical and psychological implications, as a result of differential processing. These responses were called transformation bias, scope bias and matching- 


\section{LAURA WENT TO THE BAKERY TO BUY ACHOCOLATE CAKE AND ALEMON CAKE. WHEN SHE ASKED ABOUT THE PRICES, SHE REALIZED THAT SHE DIDN'T HAVE ENOUGH MONEY TO DO THE TRANSACTION.}

Which of the following options best represents Laura's situation?

a) She does not buy the chocolate cake, or she does not buy the lemon cake, or she decides not to buy any of them. *

b) She does not buy the chocolate cake and she does not buy the lemon cake.

c) She does not buy the chocolate cake, or she does not buy the lemon cake; she chooses one of these options but not both.

d) She does not buy the chocolate cake, so she does not buy the lemon cake.

Figure 1. Sample of the task for the negation of a conjunction (Law 1).Note: The asterisk * signals the correct answer according to De Morgan’s Law 1.

JULIA RECEIVED A MEDICAL PRESCRIPTION TO DO A SPORT. THE DOCTOR TOLD HER SHE COULD PLAY TENNIS, OR SHE COULD PLAY GOLF, OR SHE COULD DO BOTH. NEVERTHELESS, JULIA IS NOT INTERESTED IN DOING WHAT WAS PRESCRIBED.

Which of the following options best corresponds better with what Julia will do?

a) If she does not play tennis, then she does not play golf.

b) She decides not to play tennis, or she decides not to play golf; she chooses one of these options but not both.

c) She decides not to play tennis, or she decides not to play golf, or she decides not to play either of them.

d) She decides neither to play tennis nor to play golf. *

Figure 2. Sample of the task for the negation of a disjunction (Law 2).Note: The asterisk * signals the correct answer according to De Morgan’s Law 1.

bias-like, according to the type of bias they referred to. Thus, the transformation bias describes the mental transformation operation performed by people as a result of an erroneous inferential effort. According to the laws established by logic, it is valid to consider the proposition «no p or no q" as the equivalent of the conditional «if p, then not q» (Suppes \& Hill, 1992). In this task, however, a different conditional was included (of «if not p, then not q» type), which is logically invalid (see Figure 1, option d; Figure 2, option a). Considering the logical aspect, it is likely that those who chose this response option made an inferential processing effort intended to represent the fully explicit mental models. Despite the effort made, however, the difficulty of the task was such that they could not complete it successfully, and this led to a wrong transformation (Macbeth et al., 2017a).

Another option offered was the so-called scope bias, associated with the processing bias proposed by Khemlani et al. (2012). This deviation is observed in the case of compound negation, according to which individuals tend to limit their interpretation to only one of the atomic propositions (small scope) and not to 
the compound proposition in its entirety (large scope) (Khemlani et al., 2012; Macbeth et al., 2013). To illustrate it better, let's check the example in Figure 1, where Laura realizes that she does not have enough money to buy a chocolate cake and a lemon cake, as intended. Finding the appropriate logical equivalent in this task requires to be able to deny both atomic propositions jointly: Laura does not buy the chocolate cake, or she does not buy the lemon cake, or she does not buy any of the two (inclusive disjunction: Figure 1, option a; Figure 2, option c). Despite this, most individuals tend to choose the option in which the propositions are denied but only separately; that is, Laura does not buy the chocolate cake, or does not buy the lemon cake; she chooses one but not both (exclusive disjunction: Figure 1, option c; Figure 2, option b).

From a logical point of view, the scope bias can be interpreted as an attempt by people to reduce the overload in their working memory and consequently the processing effort (Macbeth et al., 2017a). From a psychological perspective, however, the implications are different. If the contextual nature of the statement is remembered, it is possible that this bias was mediated by a second phenomenon called loss aversion (Tversky \& Kahneman, 1991). This refers to a behavioral tendency according to which, when having to choose, the person would show greater propensity to reduce losses rather than to increase profits (Tversky \& Kahneman, 1991). This phenomenon, originally studied in economic contexts, is nonetheless applicable whenever the person weighs losses and gains. In the case of our task, the bias is observed when the individual chooses the option that keeps some type of benefit for the agents involved. In the previous example, subjects cannot consider the idea of buying no cake at all when they intended to buy both, which explains the trend to choose the option that preserves some gain (buy at least one cake).

Finally, the third erroneous option is called matching-bias-like and is linked to superficial processing: in this case, the person chooses the answer option that contains the same propositional connector (see Figure 1, option b; Figure 2, option c). This processing, in which the statement and response option are matched according to their appearance, was proposed by Evans in the context of the Wason Selection Task (Evans, 1998). It was also detected in recent studies with similar tasks (Macbeth et al., 2013; 2017a). Accumulated evidence suggests that it is an economic process in inferential terms, since it seeks to minimize the overload in the working memory.

As noted, the used paradigm has certain characteristics that make it an optimal instrument for the study of propositional reasoning. First, the neutrality and simplicity of the format greatly facilitate the comparison between theories (Macbeth et al., 2017a). Secondly, the use of a selection task makes it possible both to control the offered answers and to manage the level of difficulty more easily (Macbeth et al., 2014b).

\section{Method}

\section{Participants}

A non-probabilistic sample of 150 students from the National University of Entre Ríos, a public university located in the city of Paraná, Argentina, was used in this study. All the participants were social sciences students with no formal training in mathematics or logic. No formal training in logic was the only exclusion criterion. This item was not directly asked to the participants, but was corroborated by the researchers in the Social Sciences program curricula. The mean age was 24.48 years old $(S D=6.64)$. Female participants $(n=77)$ accounted for $51.33 \%$ of the sample. All the participants signed an Informed Consent form. No monetary or academic rewards were given.

\section{Materials and Procedure}

Each participant received a booklet with two tasks: one aimed to evaluate compound reasoning with negation, and the other one aimed to evaluate the personality. The tasks were assigned using paper 
and pencil at the beginning of a regular class at the university. Each student had to complete it individually, without any time limit. Before starting to work, we explained the students that the instructions were given at the beginning of each task. We also indicated them that the study was not harmful or tricky, and that everyone could withdraw from the study at any moment. To evaluate reasoning, we used a sentenceequivalence task implemented in previous studies (Macbeth et al., 2014b, 2015, 2017a), in which the psychometric results that support the task and other similar ones can be found (For more details, see Campitelli, Macbeth, Ospina, \& Marmolejo-Ramos, 2016; Khemlani el al., 2014). Participants were asked to find a logical equivalence for a given compound negation. The task consisted of a total of 8 exercises: four evaluated reasoning with negation of a conjunction (De Morgan's Law 1) and four evaluated reasoning with negation of a disjunction (De Morgan's Law 2). We randomized the sequence of items and the sequence of options within each item for all the subjects. Four response options were given, that is, the normative response and three non-normative response options: scope bias, transformation bias, and matching-bias-like response. As we explained before, the first one matched De Morgan's laws. The others were developed according to the number of mental models required to process them ${ }^{-}$i.e., in line with the Mental Models Theory (Macbeth et al., 2014b).

To evaluate personality factors, we used the Adjective Checklist, an instrument developed in Argentina based on the Big Five theory (Ledesma et al., 2011). The list consists of 67 adjectives covering the five personality factors. The authors of this checklist presented evidence that supports the good psychometric properties of the instrument (Ledesma et al., 2011; Sánchez \& Ledesma, 2013). Factor analysis results were consistent with the FiveFactor Model. The internal consistency of the five scales was very good (Cronbach's á ranging from .74 to .85) and the convergent correlations with the Big Five Inventory were substantial (with Pearson's correlation levels ranging from .60 to .78). Face validity, as evaluated by two independent raters, was good. Moreover, the instrument showed a convergent validation with an Argentine version of the Big Five Inventory [BFI], adapted by Castro-Solano (2002), and Castro Solano and Casullo (2001) (For more details, see Ledesma et al., 2011; Sánchez \& Ledesma, 2013). The inventory is structured as a Likert scale with five response options: from not characteristic of me to very characteristic of me. Participants were instructed to choose a single option for each adjective.

The completion of the experiment lasted roughly 20 minutes.

\section{Design and Analyses}

A correlational cross-sectional study was conducted to test five empirical hypotheses that relate personality factors to response types in a compound reasoning task. We correlated five personality factors (neuroticism, extraversion, agreeableness, openness, conscientiousness) with four response types (normative response, transformation bias, scope bias, matching-bias-like response) for both De Morgan's laws (negation of a conjunction, negation of a disjunction). We developed a correlation matrix of $13 \times 13$ cells, that is, five (personality factors) plus eight reasoning conditions (four response types $\mathrm{x}$ two laws of logic). Since we are interested in correlates rather than manipulations, we used the $13 \times 13$ matrix instead of a $5 \times 4 \times 2$ matrix (personality factors $\mathrm{x}$ response types $\mathrm{x}$ laws of logic) required for a factorial experiment focused on the effects of controlled manipulations, and the ANOVA family of statistics to produce evidence. To perform correlational analyses, we used the non-parametric Spearman's rho and the set type I error at 0.05 . The choice to apply robust statistics was because reasoning vectors were incompatible with the assumption of normality according to KolmogorovSmirnov test. In the case of both laws, all types of responses yield $p$ values close to zero as per the aforementioned test. 


\section{Empirical Hypotheses}

We derived five empirical hypotheses from our working hypothesis. That is, we conjectured that some specific cognitive patterns can be correlated with certain personality factors during reasoning with compound negations. We focused on neuroticism, extraversion, and agreeableness. Since the reasoning task we selected requires abstraction (Macbeth et al., 2014b), we did not focus on openness to experience or conscientiousness because both are concrete experiences related rather than abstract thinking related. Moreover, due to the materials and procedure of our reasoning task, we focused on three response types: normative response, transformation bias, and scope bias. We did not consider the matching-biaslike response because it seems to be more a linguistic effect rather than a specific psychological phenomenon (Macbeth et al., 2014b). The empirical hypothesis H1 predicts a direct and significant correlation between neuroticism and transformation bias for the negation of a conjunction. $\mathrm{H} 2$ predicts a direct and significant correlation between neuroticism and transformation bias for the negation of a disjunction. H3 predicts a direct and significant correlation between agreeableness and scope bias for the negation of a conjunction. $\mathrm{H} 4$ predicts a direct and significant correlation between extraversion and scope bias for the negation of conjunction. H5 predicts an inverse and significant correlation between extraversion and normative response for the negation of a disjunction.

The relationship between neuroticism and transformation bias predicted in $\mathrm{H} 1$ and $\mathrm{H} 2$ can be justified as a psychological effect of erroneous overthinking. That is, the transformation bias response type requires more mental computation than other response types because it is formulated as a conditional. This transformation is biased both for the negation of conjunctions in $\mathrm{H} 1$, and for the negation of a disjunction in $\mathrm{H} 2$.

The scope bias response type is concerned with gains and losses, which are sensitive traits for both the extraversion and agreeableness personality factors. This kind of loss can be related to a lack of sociability skills (Ariely, 2008). Therefore, H3 is justified as an altruistic concern in a social situation. The scope bias response in our reasoning task preserves some kind of gain because the total loss is cancelled by the exclusive disjunction. Following the same line of reasoning the prediction stated in $\mathrm{H} 4$ is concerned with the same social altruism criterion. In this case, extraversion might be understood as the source of such altruistic tendency.

On the other hand, the extraversion factor is also related to characteristics such as spontaneity and impulsivity, while the normative response does it with a greater capacity for reflection and attention. In this way, the inverse and significant correlation established in $\mathrm{H} 5$ between both variables can be justified by their opposite tendencies

\section{Results}

Hypotheses H1 to H5 were consistent with the evidence. Concerning H1, participants who had higher scores in neuroticism showed a greater tendency (Spearman's rho $=.202 ; p=.013$ ) to choose the transformation bias response option in our compound reasoning task for the specific case of negation of a conjunction. Concerning H2, participants who had higher scores in neuroticism also showed a greater tendency ( $r h o=.169 ; p=.039$ ) to choose the transformation bias response option but, in this case, for the negation of a disjunction. Concerning H3, participants who had higher scores in agreeableness showed a significant tendency $(r h o=.200 ; p=.014$ ) to choose the scope bias response option for the negation of a conjunction. Concerning $\mathrm{H} 4$, the response option most frequently chosen $(r h o=.263 ; p=.001)$ by participants who had higher scores in extraversion was the scope bias response for the negation of a disjunction. In the case of H5, participants who had higher scores in extraversion exhibited a lower tendency ( $r h o=-.160 ; p=.05$ ) to choose the normative response option when reasoning with the negation of a disjunction. 


\section{Discussion}

The study results provide evidence in favor of the hypothesis that relates personality traits to reasoning patterns. In particular, it was observed that the neuroticism, extraversion, and agreeableness factors generate specific response patterns in reasoning tasks with compound negation propositions. Thus, it was found that the neuroticism factor correlates directly and significantly with the transformation bias response pattern, the extraversion factor correlates directly and significantly with the scope bias pattern, but inversely with the normative response, and the agreeableness factor correlates directly and significantly with the scope bias response.

This study works with the notion proposed by the MMT which states that thought is a semantically driven process based on the elaboration of mental models (Johnson-Laird, 1983; Johnson-Laird \& Byrne, 1991; Johnson-Laird et al, 2015, 2017, 2019). Since the creation of these representations is strongly influenced by the knowledge of the world people have, and by the significance that they attribute to their interpretations (Johnson-Laird et al, 2015, 2017, 2019; Khemlaniet al., 2012), it states that personality plays a significant role in the appearance of individual differences in compound reasoning processes. These differences would not only affect the capacity to imagine and represent mental models; they would also be partially explained by personality traits.

Previous studies have presented evidence along these lines. For example, Fumero et al. (2010) state that personality traits affect reasoning, directly influencing the quantity and quality of the represented mental models. According to this assumption, people reason better when they deal with materials related to their predominant features; they produce more representations and of greater relevance. Partial evidence was found for this hypothesis, particularly in relation to the neuroticism and extraversion traits. Additionally, other researchers notice how reasoning about real content influences the results of a task
(Markovits, Thompson, \& Brisson, 2015). Manktelow (2012) talks about thematic facilitation or reasoning biases, depending on whether the content coincides or not with the one proposed in the logic. Also, additional evidence was found in favor of the influence of pragmatic knowledge in the representation of propositions (Evans, Handley, Neilens, \& Over, 2008; Macbeth et al., 2015; Valiña et al., 2014). Finally, other researchers talk about thinking styles, referring to these as psychological characteristics conditioning the way a person learns, perceives, or thinks (Stanovich, 2012; Sternberg et al., 2008).

Although the aforementioned theories agree that the explanation of individual differences in deductive reasoning exceeds a purely cognitive or intellectual level, not all include the same nuances. This study postulates the intervention of certain personality traits in the mental representation of propositional reasoning. That is, while some theories propose a relationship at the content level, here we propose mediation at a broader level. Personality would not only influence propositional analysis but also the quantity of represented mental models, the scope of a statement interpretation, as well as the tendency to incur a certain bias.

The presented evidence is compatible with the findings of the Theory of Negation based on the MMT. The use of propositional tasks linked to De Morgan's laws makes it possible to provide support for some of their predictions. Namely, qualitative variations in reasoning with compound negations regulated by (1) the scope of the interpretation, (2) the significance and subjective reference of the connectives, and (3) the number of mental models required by a proposition (Khemlani et., 2012). Likewise, additional evidence that suggests the intervention of some personality traits as conditioning mechanisms of this process is offered. None of these findings are consistent with the theories of formal rules (Braine \& O’Brien, 1998; Rips, 1994; 2011). Unlike the MMT, these theories conceive reasoning 
as a set of rules similar to those of logic: syntactic in nature, and independent of the content and context of a proposition (Valiña et al., 2014). Also, given that these rules are considered universal, it is not possible to expect variations in the type of processing, letting alone differences related to personality.

One of the limitations of this study lies in the absence of a chronometric report. Given that latencies are important indicators of mental representations and processing difficulty, the measurement of time would have provided additional support to the offered evidence. Similarly, a source of complementary information would have been the study of patterns of eye movement with the use of eye-tracking technology (Macbeth, Razumiejczyk, Crivello, \& Fernández, 2017b). Analyzing these patterns during the development of the task, especially the registration of fixations in certain areas of interest, would have made a valuable contribution in understanding the phenomenon. Incorporating both measurements in future studies is suggested.

Although the presented portion of the analysis is limited (compared to the wide universe of reasoning and personality), the results are overwhelming. Different patterns of inferential reasoning were detected when dealing with similar formal problems. Some of these patterns were linked to personality traits. However, we acknowledge the need for further studies to replicate these findings.

Even though the questions around this process are still numerous, it is clear that any model that starts from a logical and linear conception is insufficient. In this sense, we agree with Fumero et al. (2010) on the need to increase the complexity of the approach to study the phenomenon. If we really want to achieve an approximation in the understanding of reasoning, it is not possible to leave out of the discussion factors such as knowledge, experience, context, and individual differences (in their multiple levels).

\section{Competing Interests}

The authors have declared that no competing interests exist.

\section{Ethical Responsibility}

The study was conducted on a sample of human subjects. Once the individuals were summoned, their voluntary participation was requested, guaranteeing the complete confidentiality of the data provided. We also told them that the study did not involve any harm or deception, and that everyone could withdraw from the study at any moment. Finally, the participants were asked to sign an Informed Consent form, in which they declared their free and voluntary consent to participate in the experiment

\section{Authorship Contribution}

MCC: data collection, statistical analysis, data interpretation, and discussion.

ER: Discussion and final review of the article.

GM: Conception and design of the study, interpretation of the data, discussion, and final revision of the manuscript.

\section{Funding/Financial Support}

The author(s) disclosed receipt of the following financial support for the research, authorship, and/or publication of this article: This work was supported by the National Scientific and Technical Research Council of Argentina (Grant PIPCONICET11220130100765CO). 


\section{References}

Airenti, G. (2019). The Place of Development in the History of Psychology and Cognitive Science. Frontiers in Psycholy, 10, 895. doi:10.3389/fpsyg.2019.00895

Allik, J., \& McCrae, R. R. (2002). A five-factor theory perspective. In R.R. McCrae \& J. Allik (Eds.), The fivefactor model of personality across cultures (pp. 303322). New York: Springer Science \& Business Media. doi:10.1007/978-1-4615-0763-5_15

Allport, G. (1974). Psicología de la Personalidad. (4 ${ }^{\text {th }}$ Ed.). Buenos Aires: Paidós.

Ariely, D. (2008). Predictably Irrational. Canada: Harper Collins.

Aristotle (1984). In J. Barnes (Ed.), The Complete works of Aristotle, Vols. 1 and 2, Princeton. NJ: Princeton University Press.

Bott, L., \& Noveck, I. A. (2004). Some utterances are underinformative: The onset and time course of scalar inferences. Journal of Memory and Language, 51(3), 437-457. doi:10.1016/j. jml.2004.05.006

Braine, M. D., \& O’Brien, D. P. (Eds.). (1998). Mental logic. New York: Psychology Press.

Brandt, N. D., Lechner, C. M., Tetzner, J., \& Rammstedt, B. (2019) (in press). Personality, cognitive ability, and academic performance: Differential associations across school subjects and school tracks. Journal of personality. 1-7. doi: 10.1111/jopy.12482

Campitelli, G., Macbeth, G., Ospina, R., \& MarmolejoRamos, F. (2016). Three Strategies for the Critical Use of Statistical Methods in Psychological Research. Educational and Psychological Measurement, 77(5), 881-895. doi: 10.1177/0013164416668234

Castro-Solano, A., \& Casullo, M. M. (2001). Rasgos de personalidad, bienestar psicológico y rendimiento académico en adolescentes argentinos. Interdisciplinaria, 18(1), 65-85.

Costa, P. T., \& McCrae, R. R. (1999). Inventario de Personalidad Neo Revisado (NEO PI-R). Inventario NEO reducido de cinco factores (NEO-FFI). Manual professional. Madrid: TEA Ediciones.

Costa, P. T., McCrae, R. R., \& Löckenhoff, C. E. (2019). Personality across the life span. Annual Review of
Psychology, 70, 423-448. doi: 10.1146/annurev-psych010418-103244

De Morgan, A. (1847). Formal logic: or, the calculus of inference, necessary and probable. London: Taylor and Walton.

Elqayam, S., \& Over, D. E. (2016). From is to ought: The place of normative models in the study of human thought. Frontiers in psychology, 7, 628. doi: 10.3389/ fpsyg.2016.00628

Evans, J. S. B. T. (1998). Matching bias in conditional reasoning: Do we understand it after 25 years? Thinking \& Reasoning, 4(1), 45-82. doi:10.1080/ 135467898394247

Evans, J. S. B. T., Handley, S. J., Neilens, H., \& Over, D. E. (2008). Understanding causal conditionals: A study of individual differences. The Quarterly Journal of Experimental Psychology, 61(9),1291-1297. doi: 10.1 080/17470210802027961

Fumero, A., Santamaría, C., \& Johnson-Laird, P. (2010). Formas de pensar: efecto de la personalidad en el razonamiento. Psicothema, 22(1), 57-62. Retrieved from https://www.redalyc.org/articulo.oa?id=727/72712699010

Grice, H. P. (1989). Studies in the way of words. Cambridge, MA: Harvard University Press.

Horn, L. R. (1989). A natural history of negation. Chicago, IL: The University of Chicago Press.

Horn, L. R., \& Ward, G. (2005). The handbook of pragmatics. Oxford, UK: Blackwell Publishing.

Introzzi, I., Andrés, M. L., Canet-Juric, L., Stelzer, F., \& Richard's, M. M. (2016). The relationship between the rumination style and perceptual, cognitive, and behavioral inhibition. Psychology \& Neuroscience, 9(4), 444-456. doi: 10.1037/pne0000068

Johnson-Laird, P. N. (1983). Mental models: Towards a cognitive science of language, inference, and consciousness. Cambridge, MA: Harvard University Press.

Johnson-Laird, P. N. (2006). How we reason. New York, NY: Oxford University Press.

Johnson-Laird, P. N. (2010a). Against logical form. Psychologia Belgica, 50(3-4), 193-221. doi:10.5334/pb50-3-4-193 
Johnson-Laird, P. N. (2010b). Mental models and human reasoning. Proceedings of the National Academy of Sciences, 107(43), 18243-18250. doi:10.1073/ pnas.1012933107

Johnson-Laird, P. N., \& Byrne, R. M. J. (1991). Deduction. Hillsdale, NJ: Lawrence Erlbaum.

Johnson-Laird, P. N., Goodwin, G. P., \& Khemlani, S. S. (2018). Mental models and reasoning. En L. J. Ball \& V. A. Thompson (Eds.), International handbook of thinking and reasoning (pp. 346-365). New York, NY: Routledge.

Johnson-Laird, P. N., Khemlani, S. S., \& Goodwin, G. P. (2015). Logic, probability, and human reasoning. Trends in Cognitive Sciences, 19(4), 201-214. doi: 10.1016/ j.tics.2015.02.006

Johnson-Laird, P. N., \& Ragni, M. (2019). Possibilities as the foundation of reasoning. Cognition, 193, 103950. doi: 10.1016/j.cognition.2019.04.019

Khemlani, S. S. (2018). Reasoning. Stevens' Handbook of Experimental Psychology and Cognitive Neuroscience, 3, 1-45. doi:10.1002/9781119170174.ep cn311

Khemlani, S. S., Byrne, R. M., \& Johnson-Laird, P. N. (2018). Facts and Possibilities: A Model Based Theory of Sentential Reasoning. Cognitive science, 42(6), 1887-1924. doi: 10.1111/cogs.12634

Khemlani, S. S., \& Johnson-Laird, P. N. (2017). Illusions in reasoning. Minds and Machines, 27(1), 11-35. doi: 10.1007/s11023-017-9421-X

Khemlani, S., Orenes, I., \& Johnson-Laird, P. N. (2012). Negation: A theory of its meaning, representation, and use. Journal of Cognitive Psychology, 24(5), 541-559. doi:10.1080/20445911.2012.660913

Khemlani, S., Orenes, I., \& Johnson-Laird, P. N. (2014). The negations of conjunctions, conditionals, and disjunctions. Acta Psychologica, 151, 1-7. doi:10.1016/ j.actpsy.2014.05.004

Laajaj, R., Macours, K., Hernandez, D. A. P., Arias, O., Gosling, S. D., Potter, J., \& Vakis, R. (2019). Challenges to capture the big five personality traits in non-WEIRD populations. Science advances, 5(7), eaaw5226. doi: 10.1126/sciadv.aaw522

Ledesma, R. D., Sánchez, R., \& Díaz-Lázaro, C. M. (2011). Adjective checklist to assess the Big Five personality factors in the Argentine population. Journal of Personality Assessment, 93(1), 46-55. doi:10.1080/ 00223891.2010.513708

Macbeth, G., Crivello, M.d.C., Fioramonti, M., \& Razumiejczyk, E. (2017a). Chronometrical evidence supports the model theory of negation. Sage Open, 7(2), 1-8. doi:10.1177/2158244017716216

Macbeth, G., Razumiejczyk, E., \& Campitelli, G. (2011). Relevancia de la introspección para el reconocimiento de las leyes lógicas de Augustus De Morgan. Boletín de Psicología, 101(1), 67-79.

Macbeth, G., Razumiejczyk, E., \& Crivello, M. d. C. (2014a). Efecto de la distorsión introspectiva sobre los errores de superficie en el razonamiento lógico. Boletín de Psicología, 111(2), 25-43.

Macbeth, G., Razumiejczyk, E., Crivello, M., Bolzán, C., Girardi, C. I. P., \& Campitelli, G. (2014b). Mental models for the negation of conjunctions and disjunctions. Europe's Journal of Psychology, 10(1), 135-149. doi:10.5964/ejop.v10i1.696

Macbeth, G., Razumiejczyk, E., Crivello, M., \& Fernández, J. H. (2017b). Gaze patterns of compound negation processing. Education Science and Psychology 4(46), 3-10.

Macbeth, G., Razumiejczyk, E., Crivello, M., Fioramonti, M., \& Pereyra Girardi, C. I. (2013). The shallow processing of logical negation. Psychology and Behavioral Sciences, 2, 196-201. doi:10.11648/j.pbs.20130205.15

Macbeth, G., Razumiejczyk, E., Crivello, M., Fioramonti, M., \& Pereyra Girardi, C. I. (2015). Prior Affirmative Representation Facilitates the Cognitive Processing of Compound Negation. International Journal of Psychology and Behavioral Sciences, 5(6), 205-215. doi:10.5923/j.ijpbs.20150506.02

Manktelow, K. I. (2012). Thinking and reasoning. An introduction to the psychology of reason, judgment and decision making. London \& New York: Psychology Press.

Markovits, H., Brisson, J., \& de Chantal, P. L. (2017). Logical reasoning versus information processing in the dual-strategy model of reasoning. Journal of Experimental Psychology: Learning, Memory, and Cognition, 43(1), 72-80. doi: 10.1037/xlm0000291 
Markovits, H., Thompson, V. A., \& Brisson, J. (2015). Metacognition and abstract reasoning. Memory \& cognition, 43(4), 681-693. doi:10.3758/s13421-014-0488-9

McCrae, R. R., \& Costa, P. T. (1987). Validation of the fivefactor model of personality across instruments and observers. Journal of personality and social psychology, 52(1), 81-90. doi:10.1037/0022-3514.52.1.81

McCrae, R. R., \& Costa, P. T. (1999). A five-factor theory of personality. In L. A. Pervin \& O. P. John (Eds.), Handbook of personality: Theory and research, (pp. 139-153). New York: Guilford.

McCrae, R. R., \& Costa, P. T. (2004). A contemplated revision of the NEO Five-Factor Inventory. Personality and individual differences, 36(3), 587-596. doi:10.1016/ S01918869(03)00118-1

McCrae, R. R., \& Mõttus, R. (2019). What Personality Scales Measure: A New Psychometrics and Its Implications for Theory and Assessment. Current Directions in Psychological Science, 28(4), 415-420. doi : 10.1177/0963721419849559

McCrae, R. R., \& Terracciano, A. (2005). Universal features of personality traits from the observer's perspective: data from 50 cultures. Journal of personality and social psychology, 88(3), 547-561. doi:10.1037/00223514.88.3.547

Morgan, A. de (1847). Formal logic: or, the calculus of inference, necessary and probable. London: Taylor and Walton.

Pereira, A. T., Marques, N., Soares, M. J., Valente, J., Nogueira, V., Boss, S., ... Azevedo, M. H. (2012). Worry and rumination: exploring a brief measure of repetitive thought. European Psychiatry, 27(1), 1. doi: 10.1016/ S0924-9338(12)75225-2

Restrepo, J. E. (2015). Correlatos cognitivos y neuropsicológicos de los cinco grandes: una revisión en el área de la neurociencia de la personalidad. Pensando Psicología, 11(18), 107-127. doi:10.16925/ pe.v11i18.1004

Rips, L. J. (1994). The psychology of proof. Cambridge, MA: MIT Press.

Rips, L. J. (2011). Lines of thought: Central concepts in cognitive psychology. New York, NY: Oxford University Press. doi:10.1093/acprof:oso/9780195183054.001.0001
Orenes, I., Moxey, L., Scheepers, C., \& Santamaría, C. (2016). Negation in context: Evidence from the visual world paradigm. The Quarterly Journal of Experimental Psychology, 69(6), 1082-1092. doi:10.1080/17470218.2015.1063675

Sánchez, R., \& Ledesma, R. (2007). Los cinco grandes factores: ¿cómo entender la personalidad y cómo evaluarla? Conocimiento para la transformación. Serie Investigación y Desarrollo, 131-160.

Sánchez, R. O., \& Ledesma, R. D. (2013). Listado de adjetivos para evaluar personalidad: propiedades $\mathrm{y}$ normas para una población argentina. Revista Argentina de Clínica Psicológica, 22(2), 147-160.

Sperber, D., \& Wilson, D. (1986). Relevance: Communication and cognition. Oxford, UK: Basil Blackwell.

Stajkovic, A. D., Bandura, A., Locke, E. A., Lee, D., \& Sergent, K. (2018). Test of three conceptual models of influence of the big five personality traits and self-efficacy on academic performance: A meta-analytic path-analysis. Personality and Individual Differences, 120, 238-245. doi: 10.1016/j.paid.2017.08.014

Stanovich, K. E. (2012). On the distinction between rationality and intelligence: Implications for understanding individual differences in reasoning. In K. J. Holyoak \& R. G. Morrison (Eds.), The Oxford handbook of thinking and reasoning (pp. 343-365). New York: Oxford University Press.

Sternberg, R. J., Grigorenko, E. L., \& Zhang, L. F., (2008). Styles of learning and thinking matter in instruction and assessment. Perspectives on Psychological Science, 3(6), 486-506. doi:10.1111/j.1745-6924.2008.00095.x

Suppes, P., \& Hill, S. (1992). First course in mathematical logic. Mineola, NY: Dover Publications.

Tversky, A., \& Kahneman, D. (1991). Loss aversion in riskless choice: A reference- dependent model. The quarterly journal of economics, 106(4), 1039-1061. doi:10.2307/2937956

Valiña, M. D., Martín, M., \& Seoane, G. (2014). Importancia del conocimiento pragmático en inferencia condicional: una aproximación experimental. Suma Psicólogica, 21(2), 81-88. doi:10.1016/S0121-4381(14)70010-4 
van der Linden, D., Dunkel, C. S., Figueredo, A. J., Gurven, M., von Rueden, C., \& Woodley of Menie, M. A. (2018). How Universal Is the General Factor of Personality? An Analysis of the Big Five in Forager Farmers of the Bolivian Amazon. Journal of cross- cultural psychology, 49(7), 1081-1097. doi: 10.1177/ 002202211877492

Wilson, D., \& Sperber, D. (1994). Outline of relevance theory. Links \& Letters, 1, 85-106.

\section{Maria del Carmen Crivello}

Universidad Católica Argentina (UCA), Argentina.

National Scientific and Technical Research Council (CONICET), Argentina.

PhD student in Psychology. Doctoral Fellow at the National Scientific and Technical Research Council (CONICET), Argentina; Centro de Investigación Interdisciplinar en Valores, Integración y Desarrollo Social, Facultad Teresa de Avila, pont. Universidad Católica Argentina «Sta. Maria de los Bs. As.», Argentina.

ORCID: http://orcid.org/0000-0002-0997-099X

Corresponsal author: mdccrivello@gmail.com

Eugenia Razumiejczyk

Universidad Católica Argentina (UCA), Argentina.

National Scientific and Technical Research Council (CONICET), Argentina.

$\mathrm{PhD}$ in Psychology. Research Assistant at the National Scientific and Technical Research Council (CONICET), Argentina; Centro de Investigación Interdisciplinar en Valores, Integración y Desarrollo Social, Facultad Teresa de Avila, pont. Universidad Católica Argentina «Sta. Maria de los Bs.As.», Argentina.

ORCID: http://orcid.org/0000-0003-0762-1558

eugeniaraz@hotmail.com

\section{Guillermo Macbeth}

Universidad Católica Argentina (UCA), Argentina.

National Scientific and Technical Research Council (CONICET), Argentina.

$\mathrm{PhD}$ in Psychology. Research Associate at the National Scientific and Technical Research Council (CONICET), Argentina; Centro de Investigación Interdisciplinar en Valores, Integración y Desarrollo Social, Facultad Teresa de Avila, pont. Universidad Católica Argentina «Sta. Maria de los Bs.As.», Argentina.

ORCID: http://orcid.org/0000-0001-9843-0524

g.macbeth@conicet.gov.ar 